\title{
Solving combined economic emission dispatch problem in wind integrated power systems
}

\author{
Surender Reddy Salkuti \\ Department of Railroad and Electrical Engineering, Woosong University, Daejeon, Republic of Korea
}

\begin{tabular}{l}
\hline \hline Article Info \\
\hline Article history: \\
Received Apr 19, 2020 \\
Revised Jun 15, 2020 \\
Accepted Jul 8, 2020 \\
\hline
\end{tabular}

\section{Keywords:}

Economic dispatch Emission dispatch Meta-heuristic algorithms Renewable energy Uncertainty

\begin{abstract}
A meta-heuristic based optimization method for solving combined economic emission dispatch (CEED) problem for the power system with thermal and wind energy generating units is proposed in this paper. Wind energy is environmentally friendly and abundantly available, but the intermittency and variability of wind power affects the system operation. Therefore, the system operator (SO) must aware of wind forecast uncertainty and dispatch the wind power accordingly. Here, the CEED problem is solved by including the nonlinear characteristics of thermal generators, and the stochastic behavior of wind generators. The stochastic nature of wind generators is handled by using probability distribution analysis. The purpose of this CEED problem is to optimize fuel cost and emission levels simultaneously. The proposed problem is changed into a single objective optimization problem by using weighted sum approach. The proposed problem is solved by using particle swarm optimization (PSO) algorithm. The feasibility of proposed methodology is demonstrated on six generator power system, and the obtained results using the PSO approach are compared with results obtained from genetic algorithm (GA) and enhanced genetic algorithms (EGA).
\end{abstract}

This is an open access article under the $\underline{C C B Y-S A}$ license.

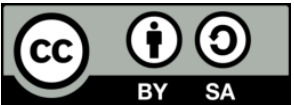

\section{Corresponding Author:}

Surender Reddy Salkuti

Department of Railroad and Electrical Engineering

Woosong University

Jayang-dong, Dong-gu, Daejeon-34606, Republic of Korea

Email: surender@wsu.ac.kr

\section{INTRODUCTION}

Wind power generation throughout the world has developed significantly over the past few decades. Renewable energy is a kind of energy source that is continuously replenished by natural processes. These renewable energy resources (RERs) include wind energy, solar thermal energy, photovoltaic energy, biomass, geothermal technology, hydroelectric with a capacity of less than 60 megawatts, tidal or wave action, and fuel cell, etc. The RERs have several advantages compared to traditional sources [1]. Some of the advantages of power generated from these RERs include: the potential for low or no fuel cost, potential to utilize relatively small, modular plant sizes, significantly reduced environmental effects compared to fossil fuels i.e., the ability to participate in climate change reduction, decrease the dependence on conventional energy resources which can minimize running operation costs, and the potential for use in distributed generation applications [2]. However, the disadvantages include: relatively high capital cost, uneven geographic distribution of RERs, intermittent or uncertain nature of power production, etc. The aim in operation of any of today's complex power system is to meet the demand for power at lowest possible cost, while maintaining the safety, reliability and continuity of service. Optimum operation can be achieved when the generating units in the system share load to minimize overall cost of generation. Constantly increasing 
fuel prices, supplies and maintenance compelled the power companies to maintain reasonable relation between the cost of power generated and the cost of delivering the power to consumers [3].

The price of energy produced depends on two factors, i.e., fixed and running costs. The fixed cost are independent of plant operation, and it consists of capital cost of power plant, interest on capital, taxes and insurance, salaries of management and clerical staff, and depreciation. Whereas, the running cost varies proportional to the electric energy produced and it consists of cost of fuel, operation cost of the plant in terms of salaries and maintenance cost. For solving the economic dispatch (ED) problem, the traditional/conventional optimization techniques cannot be applied directly because of prohibited zones (discontinuities) in the incremental cost curve [4]. Nowadays, the consideration of emission has been a major concern in power systems operation. Multi-objective based CEED is solved for minimizing fuel costs and emission which in turn determines the optimal sizing of distributed energy resources [5]. Proposes CEED for solar PV integrated power system with multiple thermal and solar PV units [6, 7]. A convex model of CEED considering RERs in a microgrid (MG) environment is solved in [8]. Proposes a multi-objective multi-verse optimization technique for solving CEED and combined heat and power EED problems [9]. A CEED is solved for the integrated regional energy system with demand response [10].

Solves short-term CEED problem of MG to improve economy and to protect environment [11]. Multi-objective CEED problem of combined heat and power generation in a large MG is proposed in [12]. An exchange market algorithm for solving CEED problem incorporating the wind generating units in the power systems is proposed [13]. Differential evolution-crossover quantum particle swarm optimization algorithm is proposed [14] for solving the CEED problem. Presents a comprehensive review of recent formulation and solution of CEED problem considering the RERs [15]. Solves CEED problem to meet required load demand at minimum operating cost and emission caused by fossil fuel based power plants [16]. In the present paper, the intermittent behavior of wind generators, ramp rates and prohibited operating zones (POZs) effects of thermal generators are included in the proposed EED model. Because of this wind forecast uncertainty, the actual power produced will differs from the scheduled power. Therefore, system operator (SO) should evaluate a risk of over-producing/under-producing the wind power. This paper formulates EED problem by considering the factors involved due to over and under estimation of wind power, and particle swarm optimization (PSO) is used to solve this EED problem. The effectiveness of proposed approach is examined on six unit test system. Through the simulation results, it is observed that solving the proposed CEED problem by using PSO provides a robust and satisfactory outcome compared to other existing algorithms. The remainder of this paper is arranged as follows. Section 2 proposes a mathematical model of proposed CEED problem. Section 3 presents the modeling of wind speed and power distribution. The simulation results are discussed in Section 4. Finally, the paper is concluded in Section 5.

\section{CEED: PROBLEM FORMULATION}

The shapes of input-output and incremental fuel rate curves are not changed by different fuels or by changes in the cost of same fuel. Consequently, if the incremental curves are plotted with incremental cost as the vertical scale, the ratio of cost of fuel being burned to cost of fuel for which the curves are drawn can be used as a multiplying factor. This factor is employed to correct for fuel cost changes for any or all of the units. By this means, it is possible to solve economic loading problem under all conditions of fuel cost. Fuel cost is the principal factor of generation cost [17].

\subsection{Economic dispatch (ED) objective}

Here, the objective of ED is expressed as the minimization of operating/fuel cost of conventional thermal and wind generators along with the factors involved due to over/under estimation of the wind power. This formulation is valid for any time period, and it is expressed as [18], minimize,

$$
F=\sum_{i=1}^{N_{G}} C_{i}\left(P_{G i}\right)+\sum_{j=1}^{N_{w}}\left[C_{w j}\left(P_{w j}\right)+C_{p, w j}\left(P_{w j, a v g}-P_{w j}\right)+C_{r, w j}\left(P_{w j}-P_{w j, a v g}\right)\right]
$$

First term is quadratic cost of thermal generators, and it is expressed as:

$$
C_{i}\left(P_{G i}\right)=a_{i}+b_{i} P_{G i}+c_{i} P_{G i}^{2}
$$

where $a_{i}, b_{i}, c_{i}$ are fuel cost coefficient for the $i^{\text {th }}$ conventional thermal generator, and the quadratic cost function will varies depending upon different fuel used. The fuel cost minimization function with valve point loading (VPL) effect is expressed as [19], minimize, 


$$
F=\sum_{i=1}^{N_{G}}\left[a_{i}+b_{i} P_{G i}+c_{i} P_{G i}^{2}+\left|d_{i} \times \sin \left(e_{i} \times\left(P_{G i}^{\min }-P_{G i}\right)\right)\right|\right]
$$

Second term is direct cost function for the wind power, and it is given by:

$$
C_{w j}\left(P_{w j}\right)=d_{j} P_{w j}
$$

Third term is penalty cost function, which accounts the concept of under-estimation of wind power. This cost function can also be related with the variance of probability distribution; normally produced above the scheduled value [20]. This function helps us to determine the excess power it might produce that the scheduled value, and this penalty cost function can be expressed by using,

$$
C_{p, w j}\left(P_{w j, a v g}-P_{w j}\right)=K_{P, j}\left(P_{w j, a v g}-P_{w j}\right)=K_{p, j} \int_{P_{w j}}^{P_{r, j}}\left(p-P_{w j}\right) f_{p}(p) d w
$$

Fourth term represents available wind power being less than forecasted wind power [21], and it is termed as the over-estimation cost. This cost function helps us to determine the deficit power it might produce from the distribution function, and it is expressed as,

$$
C_{r, w j}\left(P_{w j}-P_{w j, a v g}\right)=K_{r, j}\left(P_{w j}-P_{w j, a v g}\right)=K_{r, j} \int_{0}^{P_{w j}}\left(P_{w j}-p\right) f_{p}(p) d w
$$

As mentioned earlier, the second objective considered in this paper is the emission minimization, and it is formulated next.

\subsection{Emission dispatch objective}

The gaseous emissions are changing the global climate. Recently, the activity of exploiting clean energy was accelerated in most countries. Hence, in addition to the cost minimization objective, the scheduling model is also developed to minimize the emission levels [22]. The emission minimization objective can be expressed as, minimize,

$$
E=\sum_{i=1}^{n}\left(\alpha_{i}+\beta_{i} P_{G i}+\gamma_{i} P_{G i}^{2}\right)
$$

where $\mathrm{E}$ is the total emission release (in $\mathrm{kg} / \mathrm{hr}$ ), and $\alpha_{\mathrm{i}}, \beta_{\mathrm{i}}, \gamma_{\mathrm{i}}$ are emission coefficients of $\mathrm{i}^{\text {th }}$ generating unit [23].

\subsection{Formulation of multi-objective based EED}

The multi-objective EED optimizes both the economic dispatch and emission dispatch objectives simultaneously, and it is formulated as [24], minimize,

$$
\mu=\sum_{i=1}^{n} f_{i}(F, E)=W_{1} F+W_{2} E
$$

where $W_{1}$ and $W_{2}$ are the weight factors for cost and emission objectives. In this paper, transmission losses $\left(\mathrm{P}_{\text {loss }}\right)$ are represented as a function of generator powers through $B$-coefficients, and it is expressed as [25],

$$
P_{\text {loss }}=\sum_{i=1}^{n} \sum_{j=1}^{n} P_{G i} B_{i j} P_{G j}
$$

\subsection{Constraints}

\subsubsection{Power balance constraint}

This constraint can be expressed as [26],

$$
\sum_{i=1}^{N_{G}} P_{G i}+\sum_{j=1}^{N_{W}} P_{W j}=P_{D}+P_{\text {loss }}
$$

\subsubsection{Power generation and ramp rate limits}

The power output from thermal generator $\left(P_{G i}\right)$ by including the ramp rate limits [27] is expressed as:

$$
\max \left(P_{G i}^{\min }, P_{G i}^{0}-D R_{i}\right) \leq P_{G i} \leq \min \left(P_{G i}^{\max }, P_{G i}^{0}+U R_{i}\right)
$$

where $P_{G i}^{0}$ is power generation of $i^{\text {th }}$ generating unit at previous hour. $U R_{i}$ and $D R_{i}$ are ramp up and down limits of $i^{\text {th }}$ generating unit which are in the units of MW/h. 


\subsubsection{Prohibited operating zones (POZs) effects}

Depending on the loading conditions, the power output of conventional thermal generating units is adjusted in the dispatch problem. Feasible operating zones conventional thermal unit can be expressed as [28],

$$
P_{G i} \in\left\{\begin{array}{c}
P_{G i}^{\min } \leq P_{G i} \leq P_{G i, 1}^{l} \\
P_{G i, k-1}^{u} \leq P_{G i} \leq P_{G i, k}^{l} \quad\left(k=2, \ldots, N_{z i}\right) \\
P_{G i, N_{z i}}^{u} \leq P_{G i} \leq P_{G i}^{\max }
\end{array}\right.
$$

\section{MODELING OF WIND SPEED AND POWER DISTRIBUTION}

Nowadays, most attention has been focused on the probability distribution functions (PDFs) for wind energy applications. In this work, the Weibull PDF is used for the wind power distribution. The wind power derived will follows the stochastic nature as compared to the wind speed. Therefore, both wind speed and power output will be treated as random variables. Once wind speed (v) is characterized as a random variable, the output power ( $\mathrm{p}$ ) of the wind energy generator also characterized as a random variable through random variable transformation. Generally, the power output of wind generator will be in three ranges below cut-in wind speed $\left(\mathrm{v}_{\mathrm{i}}\right)$ the wind generator will not produce any power output. This is due to some friction losses in the wind turbine. Then, the wind speed between the cut-in speeds to the rated speed $\left(\mathrm{v}_{\mathrm{r}}\right)$, then wind power (p) will increase linearly, and it is also called as continuous range. Now, when the speed is increased above the rated speed and it is below the cut-out speed $\left(\mathrm{v}_{\mathrm{o}}\right)$ then it will always produce the rated wind power. This is a discrete PDF. Similarly, above the cut-out speed and below cut-in wind speed $\left(\mathrm{v}_{\mathrm{i}}\right)$, it will not produce any power. This is also a discrete range. The power output from a wind energy generator for a given wind speed input is expressed by following equations [29],

$$
\begin{aligned}
& p=0, \quad \text { for } v<v_{i} \text { and } v>v_{o} \\
& p=p_{r} * \frac{\left(v-v_{i}\right)}{\left(v_{r}-v_{i}\right)}, \quad \text { for } v_{i} \leq v \leq v_{r} \\
& p=p_{r}, \quad \text { for } v_{r} \leq v \leq v_{o}
\end{aligned}
$$

If it is considered that the wind speed (v) has a given distribution such as Weibull, it is then necessary to convert that distribution to a wind power distribution. To find power output ( $\mathrm{p}$ ) of wind energy generator it is required to understand the wind speed profile at a particular location. Here, Weibull PDF is considered with two parameters are used to describe the variation in wind speed. The parameter depends upon the location, height and some geographical feature. Hence, v is modeled by using Weibull PDF, and it is described as [30],

$$
f_{v}(v)=\left(\frac{k}{c}\right) *\left(\frac{v}{c}\right)^{(k-1)} \exp \left[-\left(\frac{v}{c}\right)^{k}\right] \quad 0<v<\infty
$$

The parameters of Weibull distribution $\mathrm{c}$ and $\mathrm{k}$ should be greater than zero are referred to as scale factor and shape factor, respectively. The distribution function with Weibull PDF is expressed as [30]:

$$
f_{p}(p)=\frac{k\left(v_{r}-v_{i}\right)}{c^{k_{*} p_{r}}}\left[v_{i}+\frac{p}{p_{r}}\left(v_{r}-v_{i}\right)^{k-1}\right] \exp \left[-\left[\frac{v_{i}+\frac{p}{p_{r}}\left(v_{r}-v_{i}\right)}{c}\right]^{k}\right]
$$

The proposed EED problem is solved by using the PSO algorithm, and the detailed description of PSO can be found in references [31,32].

\section{RESULTS AND DISCUSSION}

The effectiveness and suitability of proposed methodology has been tested on six generating units system. Among these 6 generating units, generator 1 is considered as wind energy generator. For thermal generators, the ramp rate and POZ limits are considered [33]. Table 1 presents the generators power, ramp rate and POZs limits. 
Table 1. Generator power, ramp rate and POZs limits of six unit system

\begin{tabular}{ccccccc}
\hline Generator Number & $P_{G i}^{\min }(\mathrm{MW})$ & $P_{G i}^{\max }(\mathrm{MW})$ & $P_{G i}^{0}(\mathrm{MW})$ & $U R_{i}(\mathrm{MW})$ & $D R_{i}(\mathrm{MW})$ & Prohibited Zones (MW) \\
\hline 1 & 0 & 100 & --- & --- & --- & --- \\
2 & 10 & 150 & 54 & 55 & 78 & {$[50,60][92,102]$} \\
3 & 35 & 225 & 114 & 55 & 65 & {$[105,117][165,177]$} \\
4 & 35 & 210 & 114 & 50 & 90 & {$[55,85][115,130]$} \\
5 & 130 & 325 & 150 & 80 & 120 & {$[80,90][230,255]$} \\
6 & 125 & 315 & 125 & 80 & 120 & {$[80,90][230,255]$} \\
\hline
\end{tabular}

A reasonable loss coefficients matrix of power system network was employed to draw the transmission line loss and satisfy the transmission capacity constraints. All the case studies are executed on 6 generating units system with the load demands of $400 \mathrm{MW}$ and $900 \mathrm{MW}$. All the programs are coded in R2018a MATLAB and executed on a PC with 8 GB RAM, $3 \mathrm{GHz}$ processor. The proposed problem is solved by using PSO, and obtained results are also compared with GA and EGA. The considered parameters of PSO are: swarm size is 50, size of particle is 12 , maximum number of generations is 200 , acceleration constants $\left(c_{1}\right.$ and $\left.c_{2}\right)$ are 2.05 , inertia weight $(\omega)$ is 1.2 . In this paper, three different studies are simulated, and they are:

- Case 1: Solving only economic dispatch problem

- Case 2: Solving only emission dispatch problem

- Case 3: Solving EED as a multi-objective optimization (MOO) problem

\subsection{Simulation results for case 1}

In this case, ED is solved by using PSO algorithm, and obtained results are also compared with GA and EGA algorithms. Here, the generator 1 is considered as a wind energy generator. The ED problem with fuel cost minimization as an objective function is solved by considering load demands of 400 MW and $900 \mathrm{MW}$. Table 2 depicts the power outputs and objective function values for Case 1 . When the load demand is $400 \mathrm{MW}$, the obtained optimum fuel costs using GA, EGA and PSO algorithms are $24831.0 \mathrm{Rs} / \mathrm{h}$, 24665.2 Rs/h and 24310.6 Rs/h, respectively. Whereas, the amount of emission released using GA, EGA and PSO algorithms are $210.16 \mathrm{~kg} / \mathrm{h}, 210.10 \mathrm{~kg} / \mathrm{h}$ and $210.04 \mathrm{~kg} / \mathrm{h}$, respectively. When the load demand is 900 MW, then the optimum fuel cost obtained by using GA, EGA and PSO algorithms is 50764.1 Rs/h, 50632.0 Rs/h and 50602.9 Rs/h, respectively.

Table 2. Power outputs and objective function values for case 1

\begin{tabular}{|c|c|c|c|c|c|c|}
\hline \multirow{2}{*}{$\begin{array}{l}\text { Power outputs and } \\
\text { objective functions }\end{array}$} & \multicolumn{3}{|c|}{ Power Demand $=400 \mathrm{MW}$} & \multicolumn{3}{|c|}{ Power Demand $=900 \mathrm{MW}$} \\
\hline & GA & EGA & PSO & GA & EGA & PSO \\
\hline$P_{W}(\mathrm{MW})$ & 18.6 & 18.7 & 18.5 & 70.2 & 72.6 & 72.8 \\
\hline$P_{G 2}(\mathrm{MW})$ & 10 & 10 & 10 & 76.3 & 73.9 & 73.6 \\
\hline$P_{G 3}(\mathrm{MW})$ & 50.3 & 51.1 & 51.3 & 179 & 179 & 179 \\
\hline$P_{G 4}(\mathrm{MW})$ & 55 & 55 & 55 & 164 & 164 & 164 \\
\hline$P_{G 5}(\mathrm{MW})$ & 148.2 & 147.6 & 147.5 & 230 & 230 & 230 \\
\hline$P_{G 6}(\mathrm{MW})$ & 125 & 125 & 125 & 210 & 210 & 210 \\
\hline$P_{\text {loss }}(\mathrm{MW})$ & 7.1 & 7.4 & 7.3 & 29.53 & 29.47 & 29.4 \\
\hline Fuel cost (Rs/h) & 24831.0 & 24665.2 & 24310.6 & 50764.1 & 50632.0 & 50602.9 \\
\hline Emission $(\mathrm{kg} / \mathrm{h})$ & 210.16 & 210.10 & 210.04 & 702.40 & 701.62 & 701.65 \\
\hline
\end{tabular}

\subsection{Simulation results for case 2}

In this case, emission minimization objective is optimized independently by using the GA, EGA and PSO algorithms. Table 3 shows the optimum power outputs and objective function values for Case 2. Here, the emission dispatch problem is solved by considering the two demands, i.e., $400 \mathrm{MW}$ and $900 \mathrm{MW}$. For $400 \mathrm{MW}$ demand, the optimum amount of emission released by using GA, EGA and PSO algorithms is $192.62 \mathrm{~kg} / \mathrm{h}, 192.13 \mathrm{~kg} / \mathrm{h}$ and $191.83 \mathrm{~kg} / \mathrm{h}$, respectively. For $900 \mathrm{MW}$ demand, the optimum amount of emission released by using GA, EGA and PSO algorithms is $650.83 \mathrm{~kg} / \mathrm{h}, 649.92 \mathrm{~kg} / \mathrm{h}$ and $649.13 \mathrm{~kg} / \mathrm{h}$, respectively. From these results, it is clear that the emission obtained is optimum, but the obtained fuel cost has been deviated from the optimum. Therefore, there is a requirement for solving the two objectives (i.e., fuel cost and emission minimizations) simultaneously. 
Table 3. Power outputs and objective function values for case 2

\begin{tabular}{ccccccc}
\hline $\begin{array}{c}\text { Power outputs and } \\
\text { objective functions }\end{array}$ & \multicolumn{2}{c}{ Power Demand $=400$ MW } & \multicolumn{3}{c}{ Power Demand = 900 MW } \\
\hline$P_{W}(\mathrm{MW})$ & 45.3 & 45.8 & 45.9 & 89.7 & 89.8 & 90.4 \\
$P_{G 2}(\mathrm{MW})$ & 10 & 10 & 10 & 109 & 109 & 109 \\
$P_{G 3}(\mathrm{MW})$ & 62.5 & 62.0 & 61.8 & 156.6 & 154.3 & 153.5 \\
$P_{G 4}(\mathrm{MW})$ & 35 & 35 & 35 & 150.3 & 151.6 & 150.9 \\
$P_{G 5}(\mathrm{MW})$ & 130 & 130 & 130 & 219.6 & 220.5 & 221.3 \\
$P_{G 6}(\mathrm{MW})$ & 125 & 125 & 125 & 205 & 205 & 205 \\
$P_{\text {loss }}(\mathrm{MW})$ & 7.8 & 7.8 & 7.7 & 30.2 & 30.2 & 30.1 \\
Fuel cost $(\mathrm{Rs} / \mathrm{h})$ & 27682.9 & 27306.3 & 27102.5 & 55106.4 & 55031.2 & 54956.9 \\
Emission $(\mathbf{k g} / \mathbf{h})$ & $\mathbf{1 9 2 . 6 2}$ & $\mathbf{1 9 2 . 1 3}$ & $\mathbf{1 9 1 . 8 3}$ & $\mathbf{6 5 0 . 8 3}$ & $\mathbf{6 4 9 . 9 2}$ & $\mathbf{6 4 9 . 1 3}$ \\
\hline
\end{tabular}

\subsection{Simulation results for case 3}

Table 4 depicts the power outputs and objective function values for Case 3 . In this case, both the objectives are optimized simultaneously. For the load demand of $400 \mathrm{MW}$, the obtained optimum values of fuel cost and emission values by using GA are $26537.4 \mathrm{Rs} / \mathrm{h}, 201.62 \mathrm{~kg} / \mathrm{h}$; by using EGA are $26530.2 \mathrm{Rs} / \mathrm{h}$, $201.63 \mathrm{~kg} / \mathrm{h}$; and by using PSO are $26520.3 \mathrm{Rs} / \mathrm{h}, 201.65 \mathrm{~kg} / \mathrm{h}$, respectively. For the load demand of 900 MW, the obtained optimum values of fuel cost and emission values by using GA are $53289.5 \mathrm{Rs} / \mathrm{h}, 681.6$ $\mathrm{kg} / \mathrm{h}$; by using EGA are $53260.3 \mathrm{Rs} / \mathrm{h}, 681.9 \mathrm{~kg} / \mathrm{h}$; and by using PSO are $53251.4 \mathrm{Rs} / \mathrm{h}, 681.8 \mathrm{~kg} / \mathrm{h}$, respectively. From the above test cases, it is observed that the PSO algorithm can obtain lower fuel cost and emission release than the GA and EGA algorithms, thus resulting in higher quality solution.

Table 4. Power outputs and objective function values for case 3

\begin{tabular}{ccccccc}
\hline $\begin{array}{c}\text { Power outputs and } \\
\text { objective functions }\end{array}$ & \multicolumn{2}{c}{ Power Demand $=400$ MW } & \multicolumn{3}{c}{ Power Demand = 900 MW } \\
\hline$P_{W}(\mathrm{MW})$ & 30.5 & 31.2 & 30.8 & 93.5 & 93.4 & 93.05 \\
$P_{G 2}(\mathrm{MW})$ & 10 & 10 & 10 & 102 & 102 & 102 \\
$P_{G 3}(\mathrm{MW})$ & 38.5 & 38.9 & 39.4 & 143 & 143.1 & 143.3 \\
$P_{G 4}(\mathrm{MW})$ & 55 & 55 & 55 & 160.2 & 160.5 & 160.8 \\
$P_{G 5}(\mathrm{MW})$ & 148.6 & 147.6 & 147.5 & 225.9 & 225.6 & 225.5 \\
$P_{G 6}(\mathrm{MW})$ & 125 & 125 & 125 & 205 & 205 & 205 \\
$P_{\text {loss }}(\mathrm{MW})$ & 7.65 & 7.66 & 7.69 & 29.59 & 29.60 & 29.60 \\
Fuel cost $(\mathbf{R s} / \mathbf{h})$ & $\mathbf{2 6 5 3 7 . 4}$ & $\mathbf{2 6 5 3 0 . 2}$ & $\mathbf{2 6 5 2 0 . 3}$ & $\mathbf{5 3 2 8 9 . 5}$ & $\mathbf{5 3 2 6 0 . 3}$ & $\mathbf{5 3 2 5 1 . 4}$ \\
Emission $(\mathbf{k g} / \mathbf{h})$ & $\mathbf{2 0 1 . 6 2}$ & $\mathbf{2 0 1 . 6 3}$ & $\mathbf{2 0 1 . 6 5}$ & $\mathbf{6 8 1 . 6}$ & $\mathbf{6 8 1 . 9}$ & $\mathbf{6 8 1 . 8}$ \\
\hline
\end{tabular}

\section{CONCLUSION}

This paper proposes an economic emission dispatch (EED) considering thermal and wind energy generating plants. An algorithm have been developed to find global or near-global optimal solution of EED problem considering generator constraints, i.e., ramp rate and prohibited operating zones effects. The proposed approach has been tested on six unit system. The results obtained from particle swarm optimization are also compared with genetic algorithms and enhanced genetic algorithm. The results proved that the PSO algorithm has demonstrated an ability to provide feasible and accurate solutions within the reasonable computational time.

\section{ACKNOWLEDGEMENTS}

This research work has been carried out based on the support of "Woosong University's Academic Research Funding-(2020-2021)".

\section{REFERENCES}

[1] S. Padhi, B.P. Panigrahi, D. Dash, "Solving Dynamic Economic Emission Dispatch Problem with Uncertainty of Wind and Load Using Whale Optimization Algorithm," Journal of The Institution of Engineers (India): Series B, vol. 101, pp. 65-78, 2020.

[2] S. Jiang, C. Zhang, W. Wu, S. Chen, "Combined Economic and Emission Dispatch Problem of Wind-Thermal Power System Using Gravitational Particle Swarm Optimization Algorithm," Hindawi, Mathematical Problems in Engineering, vol. 2019, no. 2, pp. 1-19, 2019. DOI. 10.1155/2019/5679361.

[3] M.E. Alshammari, M.A.M. Ramli, I.M. Mehedi, "An Elitist Multi-Objective Particle Swarm Optimization Algorithm for Sustainable Dynamic Economic Emission Dispatch Integrating Wind Farms”, Sustainability, vol. 12, no. 18,2020 . DOI. $10.3390 /$ su12187253.

[4] E.E.Elattar, "Combined Economic Emission Dispatch for Microgrid Considering Solar and Wind Power Cost Functions Using Harmony Search Algorithm," International Journal of Applied Engineering Research, vol. 13, no. 5, pp. 3083-3092, 2018. 
[5] B. Dey, S.K. Roy, B. Bhattacharyya, "Solving multi-objective economic emission dispatch of a renewable integrated microgrid using latest bio-inspired algorithms," Engineering Science and Technology, an International Journal, vol. 22, no. 1, pp. 55-66, 2019.

[6] N.A. Khan, G.A.S. Sidhu, F. Gao, "Optimizing Combined Emission Economic Dispatch for Solar Integrated Power Systems,” IEEE Access, vol. 4, pp. 3340-3348, 2016. DOI. 10.1109/ACCESS.2016.2587665.

[7] M.M. Kumar, A.A. Rani, V. Sundaravazhuthi, "Emission Constrained Economic Dispatch with PV Energy Penetration," International Journal of Innovative Technology and Exploring Engineering, vol. 8, no. 12, pp. 3021-3026, 2019.

[8] E.B. Elanchezhian, "Combined Economic Emission Dispatch Considering Renewable Energy Sources," International Journal of Scientific \& Technology Research, vol. 8, no. 11, pp. 1222-1225, 2019.

[9] A. Sundaram, "Multiobjective multi-verse optimization algorithm to solve combined economic, heat and power emission dispatch problems," Applied Soft Computing, vol. 91, 2020.

[10] L. He, Z. Lu, L. Geng, J. Zhang, X. Li, X. Guo, "Environmental economc dispatch of integrated regional energy system considering integrated demand response," International Journal of Electrical Power \& Energy Systems, vol. 116, 2020.

[11] Z. Xin-gang, Z. Ze-qi, X. Yi-min, M. Jin, "Economic-environmental dispatch of microgrid based on improved quantum particle swarm optimization," Energy, vol. 195, 2020.

[12] M.I. Alomoush, "Microgrid combined power-heat economic-emission dispatch considering stochastic renewable energy resources, power purchase and emission tax," Energy Conversion and Management, vol. 200, 2019.

[13] M.T. Hagh, S.M.S. Kalajahi, N. Ghorbani, "Solution to economic emission dispatch problem including wind farms using Exchange Market Algorithm Method," Applied Soft Computing, vol. 88, 2020.

[14] Z. Xin-gang, L. Ji, M. Jin, Z. Ying, "An improved quantum particle swarm optimization algorithm for environmental economic dispatch," Expert Systems with Applications, vol. 152, 2020.

[15] N.F. Aswan, M.N. Abdullah, A.H.A. Bakar, "A review of combined economic emission dispatch for optimal power dispatch with renewable energy," Indonesian Journal of Electrical Engineering and Computer Science, vol. 16, no. 1, pp. 33-40, 2019.

[16] M.A. Meziane, Y. Mouloudi, A. Draoui, "Comparative study of the price penalty factors approaches for Biobjective dispatch problem via PSO," International Journal of Electrical and Computer Engineering, vol. 10, no. 4, pp. 3343-3349, 2020.

[17] C.A.O.D. Freitas, R.C.L. Oliveira, D.J.A.D. Silva, J.C. Leite, J.D.A.B. Junior, "Solution to Economic-Emission Load Dispatch by Cultural Algorithm Combined With Local Search: Case Study," IEEE Access, vol. 6, pp. 6402364040, 2018. doi: 10.1109/ACCESS.2018.2877770.

[18] S.S. Reddy, P.R. Bijwe, A.R. Abhyankar, "Joint Energy and Spinning Reserves Market Clearing for Wind-Thermal Power System Incorporating Wind Generation and Load Forecast Uncertainties," IEEE Systems Journal, vol. 9, no. 1, pp. 152-164, 2015.

[19] X. Liu, W. Xu, "Minimum Emission Dispatch Constrained by Stochastic Wind Power Availability and Cost," IEEE Transactions on Power Systems, vol. 25, no. 3, pp. 1705-1713, 2010. doi: 10.1109/TPWRS.2010.2042085.

[20] S.S. Reddy, "Multi-Objective based Optimal Energy and Reactive Power Dispatch in Deregulated Electricity Markets," International Journal of Electrical and Computer Engineering, vol. 8, no. 5, pp. 3427-3435. 2018.

[21] S.C. Kim, S. Surender Reddy, "Optimal power flow based congestion management using enhanced genetic algorithms," International Journal of Electrical and Computer Engineering (IJECE), vol. 9, no. 2, pp. 875-883, 2019.

[22] S.S. Reddy, P.R. Bijwe, A.R. Abhyankar, "Multi-Objective Market Clearing of Electrical Energy, Spinning Reserves, and Emission for Wind-Thermal Power System," International Journal of Electrical Power \& Energy Systems, vol. 53, pp. 782-794, 2013.

[23] S. Yao, S. Zhang, X. Zhang, "Renewable energy, carbon emission and economic growth: A revised environmental Kuznets Curve perspective," Journal of Cleaner Production, vol. 235, pp. 1338-1352, 2019.

[24] D. Nong, T.H. Nguyen, C. Wang, Q.V. Khuc, "The environmental and economic impact of the emissions trading scheme (ETS) in Vietnam,” Energy Policy, vol. 140, 2020.

[25] M. Kheshti, X. Kang, J. Li, P. Regulski, V. Terzija, "Lightning flash algorithm for solving non-convex combined emission economic dispatch with generator constraints," IET Generation, Transmission \& Distribution, vol. 12, no. 1, pp. 104-116, 2018.

[26] E.E. Elattar, "Modified harmony search algorithm for combined economic emission dispatch of microgrid incorporating renewable sources," Energy, vol. 159, pp. 496-507, 2018. DOI. 10.1016/j.energy.2018.06.137.

[27] S.S. Reddy, P.R. Bijwe, "Efficiency Improvements in Meta-Heuristic Algorithms to Solve the Optimal Power Flow Problem,” International Journal of Electrical Power \& Energy Systems, vol. 82, pp. 288-302, 2016.

[28] S.S. Reddy, P.R. Bijwe, A.R. Abhyankar, "Faster Evolutionary Algorithm Based Optimal Power Flow using Incremental variables," International Journal of Electrical Power \& Energy Systems, vol. 54, pp. 198-210, 2014.

[29] J. Hetzer, D.C. Yu, K. Bhattarai, “An Economic Dispatch Model Incorporating Wind Power," IEEE Transactions on Energy Conversion, vol. 23, no. 2, pp. 603-611, 2008. doi: 10.1109/TEC.2007.914171.

[30] S.S. Reddy, "Optimal scheduling of wind-thermal power system using clustered adaptive teaching learning based optimization," Electrical Engineering, vol. 99, no. 2, pp. 535-550, 2017.

[31] M.Z. Gargari, M.N. Heris, B.M. Ivatloo, "Chapter 30-Application of Particle Swarm Optimization Algorithm in Power System Problems," Handbook of Neural Computation, Academic Press, pp. 571-579, 2017.

[32] W. da Rosa, C. Gerez, E. Belati, "Optimal Distributed Generation Allocating Using Particle Swarm Optimization and Linearized AC Load Flow," IEEE Latin America Transactions, vol. 16, no. 10, pp. 2665-2670, 2018.

[33] C. Palanichamy, K. Srikrishna, "Economic thermal power dispatch with emission constraint," Journal of Institution of Engineers (India), vol. 72, pp. 11-18, 1991. 